\title{
Resuscitation skills and doctors working in psychiatry
}

\author{
Gordon McNaughton, David J. Hall and Cameron Stark
}

\begin{abstract}
Doctors working in psychiatiy have been shown to lack practical skills in basic cardiac life support (BCLS), but these have not been regarded as priortiles for troining. This study ascessed lovels of experience, conilidence and skill in BCLS, in peychiatists, and examined the effect of a single training sesston on practical skills. Lovels of skill were generally poor but signilicant improvement was seen following training. If is recommended that all poychiatitsts undergo brief regular practical training in BCLS.
\end{abstract}

The Scottish Health Service Advisory Council Working Group on Cardiopulmonary Resuscitation (1992) have emphasised the importance of training in cardiopulmonary resuscitation (CPR). The working group stated that medical staff in non-acute specialities should be able to perform basic cardiac life support (BCLS), which includes the recognition of a cardiac arrest and performance of basic CPR.

Junior doctors working in psychiatry have not been regarded as priorities for training in BCLS, and a recent study (Kosky \& Spearpoint, 1993) found that a group of psychiatric trainees lacked recent appropriate training and exhibited insufficient theoretical and practical knowledge and skills of BCLS. Their conclusion was that these inadequacies were 'a suitable case for treatment' but the type and effect of treatment was not examined.

This study assessed levels of skill and training in BCLS in psychiatrists and examined the effect on their practical skills of a single training session.

\section{The study}

Psychiatrists of all grades were invited to attend a 'practical resuscitation session' where they completed questionnaires regarding their training and confidence in BCLS. Each then had their practical performance of BCLS measured using a Laerdel Skillmeter Resusci Annie, and scored using the Nijmegan system (Berden et al, 1992). This was repeated following brief practical instruction and demonstration of the correct technique to the group. The total teaching time did not exceed 30 minutes.

\section{Findings}

Teaching sessions took place in two psychiatric hospitals, eight clinicians participating in the first and 11 in the second (six consultants and 13 junior doctors).

\section{Questionnaire data}

Previous training. Fifty-eight per cent (11) had received training in BCLS as undergraduates, $58 \%$ as residents and $26 \%(5)$ as junior doctors in other specialities but only $21 \%$ (4) while working in psychiatry. Thirty-seven per cent (7) had been involved in a resuscitation attempt in a psychiatric setting; 47\% (9) had not consulted BCLS training materials of any kind in the previous 12 months.

Confidence levels. When asked to rate their own levels of competence in BCLS and their theoretical knowledge on a 7 point scale $(0=$ 'not at all good', 7='extremely good'), 74\% gave themselves scores of 4 or less (mean=3.3, s.d. $=1.7$ ) and $95 \%$ (17) felt that they would benefit from further training in BCLS; 85\% (16) felt that such training should be repeated at least annually.

\section{Practical skills}

Six out of 13 who participated in the preinstruction evaluation of BCLS skills made an 'adequate' initial assessment, as judged by the trained assessor (GMcN), the remainder failing to assess conscious level, check and maintain an airway, check circulation, or check breathing properly. Scores on the mannequin ranged from 15-85 penalty points, using the Nijmegan scoring system in which a perfect performance scores zero (Berden et al, 1992) with eight scoring greater than 40 (mean=48, s.d. $=17.8$ ). Comparing those (4) who judged themselves as at least 'competent' on the questionnaire with those less confident, revealed no significant differences in performance on the mannequin. Those (6) who had received instruction in BCLS in the previous two years did have a lower mean score of $\mathbf{3 3 . 7 5}$ (range 15-50, s.d. $=16.52$ ) than those (7) whose 
last instruction had been more than two years previously (mean $=53.6$, s.d. $=15.67$, range $35-$ 85).

When re-tested on the mannequin following the brief group instruction session, all 13 made adequate initial assessment, and the mean score of the group fell to 29.23 (s.d.=8.13, range 1545). This was a statistically significant improvement in the group's mean scores $(P<0.05)$.

\section{Comment}

This study confirms that doctors working in psychiatry generally do not show adequate levels of skill in BCLS, although they may be involved in resuscitation attempts. Their performance in a practical test is not related to their confidence but is best in those who have received more recent instruction.

Retesting of practical skills immediately following a brief teaching session reveals significant improvements in performance.

Previous studies suggest that these skills decay and will reach pre-instruction levels within a year, particularly in groups infrequently involved in resuscitation (Fossel et al, 1983). Participants in this study were, however, generally enthusiastic about at least annual retraining.

\section{Recommendation}

A brief training session in BCLS incorporating hands-on experience with a mannequin, and the opportunity for immediate feedback from a trained instructor, is viewed positively by partici- pants and will significantly improve their BCLS skills. Such a session should be offered to all doctors working in psychiatry at least annually and possibly every six months.

\section{Acknowledgements}

We would like to thank the doctors who participated in this study and Fiona MacKay of Lundbeck who, as an educational service to psychiatry, sponsored the meetings at which these sessions took place.

\section{References}

Berden, H.J.J.M., PIJL, N.H.J., WILEMS, F.F., HENDRICK, J.M.A. \& CRUL, J.F. (1992) A scoring system for basic cardiac life support skills in training situations. Resuscttation, 23, 21-31.

Fossel, M., KISKADdon, R.T. \& STERNBACK, G.L. (1983)

Retention of cardiopulmonary skills by medical students. Journal of Medical Education, 88, 568-575.

KOKSY, N. \& SPEARPOINT, K. (1993) Resuscitation skills of psychiatric trainees - a suitable case for treatment? Psychiatric Bulletin, 17, 489-491.

WORKING GROUP On CARDIOPULMONARY RESUSCITATION (1991) Working Group on Cardiopulmonary Resuscitation Report. Scottish Health Service Advisory Council.

Gordon McNaughton, Senior House Officer in Accident and Emergency, Western Infirmary and Gartnavel General Hospital, Glasgow; "David J. Hall, Senior Registrar in Psychiatry, Leverndale Hospital, Glasgow G53 7TU; and Cameron Stark, Senior Registrar in Public Health Medicine, Argyl and Clyde Health Board

*Correspondence 